Article

\title{
Presumed Effects of "Fake News" on the Global Warming Discussion in a Cross-Cultural Context
}

\author{
Seong Choul Hong \\ Department of Media, Kyonggi University, Seoul 03746, Korea; hong21@kyonggi.ac.kr
}

Received: 6 February 2020; Accepted: 5 March 2020; Published: 9 March 2020

check for updates

\begin{abstract}
Fake news" on global warming is widely disseminated via social and partisan media. Scientists worry about its effect, because fake news may hurt public support and change policy on climate change. The current study tested the roles of cultural constructs (individualism, collectivism, and uncertainty-avoidance) in predicting the presumed effect of fake news on global warming. Based on 770 answers in four countries, the study found that individualism and collectivism influenced the presumed media effect on others and the third-person effect (self-other disparity of media effect). Moreover, the presumed media effect contributed to both preventive actions such as support for regulation on fake news and corrective actions such as a willingness to donate money. Likewise, the study found that collectivism positively predicted a willingness to donate money, while uncertainty-avoidance predicted support for regulation.
\end{abstract}

Keywords: fake news; global warming; presumed media effect; corrective action; collectivism; uncertainty-avoidance

\section{Introduction}

The controversy on global warming is enough to raise questions about our capacity of scientific knowledge [1]. Despite most scientists' recognition of man-made climate change, there are some that argue against its importance. Famous politicians, like U.S. President Trump, further fuel the debate by asserting that increased global temperatures are a natural climate shift and not caused by greenhouse gases [2,3].

Recently, mass media and social media platforms have become tools to disseminate fake news with climate change skepticism [4]. The media's skepticism about global warming may change perceptions, beliefs, and behavior or reinforce existing knowledge [5]. Further, the spread of fake news on global warming may eventually hurt public support for climate policy [6].

With worries over the effect of fake news on global warming, estimation of media effect on fake news asks us to rethink our cognitive biases such as self-serving biases or attribution bias effect [7-9]. Cognitive biases emphasize a tendency to under-estimation media effect on self or over-estimation of media effect on others, which leads to the third-person perception [10]. Over the last 40 years, the third-person effect has been persistently proved to be robust [11-13]. Among scholars, there is a consensus that the third-person effect consists of the perceptual and behavioral components [13,14].

Empirical research on the third-person effect conducted in a cross-cultural context effect often encounters a doubtful and paradoxical fact that countries with smaller third-persons perception have more content regulations than countries with larger third-person perceptions [15-17]. In this vein, the third-person perception itself may not always have a causal relationship with its behavior.

The current study explores the paradoxical spot with fake news on global warming. Scientific messages are subject to third-person effect if their messages contain either socially acceptable content or unacceptable content. Global warming, despite scientific consensus, may exist beyond our ken 
and is an object of subjective social desirability. Based on different levels of cultural constructs: individualism (IND), collectivism (COL), and uncertainty-avoidance (UA), this study explores the relationship between third person perception and related behaviors.

Based on a survey with 770 respondents in four countries (India, Korea, Spain and the United States), the study tested whether cultural constructs (IND, COL, and UA) contributed to the increase of the presumed media effect and third-person perception. At the same time, the question of how cultural constructs moderate the magnitude of the collective action becomes another aim of this study.

\section{Literature Reviews}

\subsection{Fake News of Global Warming}

The topics of fake news include politics, terrorism, crime, natural disasters, and finance. However, science also falls prey to fake news. Specifically, global warming is one of the most exploited science topics of fake news. Several scientific findings support the global warming phenomenon as an unarguable scientific fact. Indeed, the Intergovernmental Panel on Climate Change (IPCC) Report [18] states that the evidences for climate change are unequivocal; with evidences over the last 110 years of a 0.8 degree Celsius rise in global surface temperatures, a 0.19 meters rise in global mean sea levels, and an increase in the atmospheric concentrations of greenhouse gases.

Nonetheless, fake news on global warming is easily found in social network sites such as YouTube, and Facebook. This fake news casts doubt on our beliefs about global warming and man-made climate changes. Moreover, U.S. President Trump recently highlighted fake news on global warming when he revealed skepticism toward global warming by repeatedly tweeting that humans are not the primary cause of global warming [19]. He has tweeted more than 120 times on global warming since 2005. Furthermore, the Trump administration has not played a key leadership role in international effect to climate changes or in developing the Paris Agreement. Because partisan politicians and the media further exploit the issue of climate change; seeing it as an opportunity to confirm their own ideological beliefs, the climate change becomes an issue related to political ideology [20].

While seven in ten Americans (70\%) think global warming is happening, $28 \%$ of Americans continue to believe that global warming is natural and $14 \%$ that it's not even happening [21]. Specifically, the partisan media and social media platforms insulate Americans in "echo chambers" giving them selective exposure to content consistent with their opinions [22]. Thus, reinforcing existing partisan attitudes toward climate change skepticism widely proceeds $[23,24]$. Since young people may have trouble separating authentic information from fabricated facts [25], skepticism toward global warming may be more prevalent in the future.

To some extent, we may have a tendency to exaggerate fake news effect. A survey conducted by the Pew Research Center [26] reported that some $84 \%$ of respondents were very or somewhat confident in their own ability to detect fake news. However, $64 \%$ of respondents said that fake news created confusion among other Americans. The discrepancies of media effect are enough to remind the third-person effect, which as Davison [13] suggested, "Its [media's] greatest impact will not be on 'me' or 'you,' but on 'them'"' (p. 3).

\subsection{Third Person Perceptions in a Cross-Cultural Context}

Extensive examination of the third person perception has turned out to be quite robust $[11,13,27,28]$. Interestingly enough, this theory does not directly examine the media effect on perceptions. Instead, it tests how perceptions influence the media effect. In this vein, the third-person theory is based on the belief that "perceptions can shape media" ([8], p. 490). Perceptions about the effect of the media lead to certain behaviors, such as support for the regulation of media content.

In various scholarly studies, psychological theories used the over-estimation of media effect on others or under-estimation media effect on self. For example, Gunther [7] employed self-enhancement for the third-person effect's explanation. That is, people have motivations to think well of themselves. 
Optimistic biases account for under-estimation of media effect on self [29]. Since self-enhancement bias or optimistic bias varies across cultures [30-32], third person effect can be tested and compared in a cross-cultural context. To date, third person effect in most cross-cultural examinations has been tested on the dichotomy of individualism (IND) versus collectivism (COL) societies $[15,33,34]$, because variations in IND and COL consist of the most salient differences between Western and Eastern cultures [35].

In theory, IND has a trait of distinct and independent of social context [36] and people's sense of personal identity and the degree to which they seek self-actualization [37]. By contrast, COL proposes inter-dependent of social environments [38]. Thus, Markus and Kitayama [39] believed in characterizing the self-construal of IND as independence and COL as interdependence, respectively.

In a cross-cultural comparison, Cho and Han [15] found that the third-person perception was larger among the American samples than the Korean samples. Considering the fact that the Americans were significantly higher on IND than the Koreans, IND suggests a predictor of the third-person perceptions in comparing cultural differences. Similarly, Lee and Tamborini [40] tested the third-person perceptions with Internet pornography. As predicted, the United Stated has a higher third-person perception than the Korean sample in their research. Based on previous studies, this study proposes the following research hypotheses:

Hypothesis 1 (H1) -People may have a tendency to overestimate the effect of fake news on others than on self or underestimate the effect on self than on others.

Hypothesis 2-1 (H2-1) - The higher IND scores people have, the larger third-person perception they have.

Hypothesis 2-2 (H2-2) - The lower COL scores people have, the larger third-person perception they have.

\subsection{Corrective Actions as the Third Person Effects}

In spite of a larger third-person perception in the individualistic societies, these societies tend to have smaller support for regulations as consequences of the perceptual gaps than collectivist societies do. Indeed, the higher support for the censorship of internet pornography in the Korean society than in the U.S. society [40]. A recent study by Detenber and Rosenthal [16] found more support for media censorship and bigger social pressure to conform in a collectivist society than in an individualistic society. After measured COL and IND scores in Korea and the United States, Hong [17] noted IND as a factor of the third-person perception, while COL significantly predicted a positive support for regulating violent video games. Namely, IND and COL work differently at the perceptual levels and the behavioral levels of the third-person effect.

Some restrictive behaviors and corrective actions are mentioned as consequences of the third-person perception $[28,41,42]$. Corrective actions refer to an attempt to correct perceived something wrong. Instead of support censorship, people may take educational or protective measures to shield possible victims [28]. Jang and Kim [41] found that the third-person perception of fake news positively associated with media literacy education in order to minimize the potential harm of fake news. Similarly, the third-person perception predicted to add education elements to reality TV shows [28].

Some scholars insist that the presumed media effect on others, instead of the third-person perception, should be the main predictor of the corrective behavior in exploring the relationship of the third-person perception and its behavior [28,43]. Gunther and Storey [44] argue that the third-person effect is a special case of the presumed media effect in general. Similarly, Tsfati, Cohen, and Guther [45] found that scientists' presumed media effect indirectly associated with their media appearances. In this vein, it is important to investigate the roles of the presumed media effect and the third-person perception at the same time. Based on previous research this study proposes the following hypotheses:

Hypothesis 3-1 (H3-1) - The third-person perception positively predicts the likelihood of undertaking preventive action against fake news. 
Hypothesis 3-2 (H3-2) - The presumed media effect on others positively predicts the likelihood of undertaking corrective action against fake news.

\subsection{Corrective Actions in the Cross-Cultural Context}

To some extent, COL is similar to paternalism, defined as acting like a parent and seeking preventive actions with good intentions [46]. As an extension of family boundaries in a society, the paternalistic need is an explanation of behavioral consequences of the third-person perception $[47,48]$. In this vein, COL offers an explanation for the behavioral component of the third-person perception as paternalism does. That is, corrective action to rectify something wrong can be understood with a COL behavior.

Considering regulation associates with UA tendency [35], the behavioral component of the third-person perception may be explained with the uncertainty reduction theory, which explain why people monitor how the others react after being exposed to media messages [49]. In addition, Gahagan [50] argues that regardless of its accuracy, the presumed media effect on others and subsequent behaviors reduces anxiety or uncertainty. Shuper, Sorrentino, Otsubo, Hodson, and Walker [51] found Canadian students were more oriented toward uncertainty than certainty, while Japanese students were more oriented toward certainty than uncertainty. They further argued that Canadians handle uncertainty differently from the Japanese who seek out related information. However, the uncertainty oriented in Japan developed a self-regulatory compensation in order to circumvent uncertainty.

If the over-estimation of the media's influence on others helps people to prepare for the worst situations which might harm self; people living in high uncertainty-avoiding countries, tend to have a greater need for restraining the others' behaviors in advance through the rule-making process [35]. In this vein, the UA's role in estimating the media's effect on others associates with restrictive behaviors. In a research, Hong [17] found that the UA also contributed to a higher level of consents to media regulation. It is important to consider two behaviors of third-person perceptions in terms of fake news on global warming: restriction of fake news distribution and support for donations to decrease global warming and its education. The former can be defined as restrictive behavior, and the latter is a corrective action. Based on the previous studies, this study proposes the following research hypotheses:

Hypothesis 4-1 (H4-1) —COL positively predicts the likelihood of undertaking preventive action against fake news.

Hypothesis 4-2 (H4-2) - UA positively predicts the likelihood of undertaking corrective action against fake news.

\section{Methods}

The present study explores the third-person perceptions of fake news and related behaviors in a cross-cultural context. Since the aim of the study is to test cultural constructs and their influences on third-person perceptions and corrective actions, the researcher recruited participants from countries with different levels of cultural constructs (IND, COL, and high \& low UA). Based on Hofstede's cultural values [35], this study chose Spain (IND and high UA), United States (IND and low UA), Korea (COL and high UA), and India (COL and low UA). To recruit survey participants, email invitations were sent to pre-registered online research panels in the four countries. The participants were provided the monetary incentives amount to one U.S. dollar to enhance responses. A total of 770 people responded to an online survey through Qualtrics Panels with conditions of gender and age splits in May 2017.

Participants Descriptive statistics showed that $50.8 \%$ were male, $49.2 \%$ were female. The highest percentage of males was in India (53.8\%) and Spain. The United States had 50.8\%, respectively. In the Korean samples, females (51.5\%) were little higher than males (48.5\%). Average ages of the participants were 45.5 years. Average ages ranged from 44.91 (Korea) to 46.44 (U.S.). In terms of education, $66.2 \%$ of the American participants, $61.1 \%$ of the Korean participants, $59.6 \%$ of Spain participants, and $51.4 \%$ of India participants held 4-year college degrees or higher. 
Cultural constructs Although IND and COL originally conceptualized as mutually exclusive and bipolar dimensions [35,52], this study considered them to be two separate constructs [53,54]. The seven-item individualism and eight-item collectivism scales from the study conducted by Oyserman, Coon, and Kemmelmeier [53] were adopted. The average mean score for individualism and collectivism among 770 respondents was 5.4130 and 4.5260 , respectively (see Table 1). The UA questionnaires culled from the studies of Hofstede [35] and Jung and Kellaris [55]. The average mean score for uncertainty-avoidance was 4.6994 [56].

Table 1. Difference of cultural constructs among four countries.

\begin{tabular}{cccc}
\hline & \multicolumn{3}{c}{ Cultural Constructs } \\
\cline { 2 - 4 } & IND & COL & UA \\
\hline India (169) & 5.6548 & 5.2056 & 4.7337 \\
Korea (229) & 5.4891 & 4.3231 & 5.0895 \\
Spain (183) & 4.8944 & 4.6079 & 4.5027 \\
US (189) & 5.5067 & 4.0847 & 4.3862 \\
Total (770) & 5.4130 & 4.5260 & 4.6994 \\
\hline
\end{tabular}

Presumed media effect Respondents were asked to estimate the influence of fake news on the self and others in general. Two sets of questions were asked: How much do you think that TV news arguing that global warming was hoaxed will affect (a) other people's thinking in your country on climate change (b) your thinking on climate change? After measuring responses in the seven Likert scales, subtraction estimation media effect on self (1) and from the estimation media effect on others (a) calculated the third-person perception.

Regulations and Donations Support to regulation of fake news or the intention to donate included the questions "how much do you think TV news arguing that global warming was hoaxed should be censored" and "I would donate my money to environment protection organization in order to prevent global warming," respectively.

\section{Results}

\subsection{Third Person Perception of the Fake News}

The study tested whether the third-person perceptions of fake news actually occurred. As Table 2 shows, perceived media effect on self and others had significant discrepancies in the four nations, $\mathrm{t}$ $(769)=11.886, p<0.001$. The United States had the largest third-person perception, $\mathrm{t}(188)=8.092, p<$ 0.001 and India had the smallest third-person perception, $\mathrm{t}(168)=2.817, p<0.01$. As hypothesis 1 predicted the third-person perception, it supported the H1.

Table 2. Perceived influence of fake news on self and others.

\begin{tabular}{ccccccc}
\hline & $\begin{array}{c}\text { Effect on } \\
\text { others (a) }\end{array}$ & $\begin{array}{c}\text { Effect on } \\
\text { self (b) }\end{array}$ & T-test values & $\begin{array}{c}\text { TPP } \\
(\mathbf{c}=\mathbf{a}-\mathbf{b})\end{array}$ & Regulation & Donations \\
\hline India (169) & 5.1834 & 4.9231 & $2.817^{* * *}$ & 0.2604 & 4.6686 & 4.9112 \\
Korea (229) & 4.3319 & 3.9607 & $5.725^{* * *}$ & 0.3712 & 4.4498 & 4.5502 \\
Spain (183) & 4.2077 & 3.2514 & $6.966^{* * *}$ & 0.9563 & 3.9672 & 3.7158 \\
US (189) & 4.5503 & 3.5714 & $8.092^{* * *}$ & 0.9788 & 3.9048 & 4.3862 \\
Total (770) & 4.5429 & 3.9078 & $11.886^{* * *}$ & 0.6357 & 4.2494 & 4.3909 \\
\hline
\end{tabular}

${ }^{1}$ TPP: third-person perception, ${ }^{* *} p<0.01,{ }^{* * *} p<0.001$.

Even though India has a higher IND score than the United States, the third-person perception was smallest. That is, IND by itself is not enough explanation for the third-person perception. The presumed media effect on others and on self were highest in Indian, while the presumed media effect 
on other was relatively high and the presumed media effect on self was relatively low in the United States. Table 3 shows the mean difference of variables among the four countries. In spite of the big differences in IND between Spain and India, the differences in the third person effect was not the biggest. At the same time, the gaps in the COL and UA did not consistently lend explanation for the third person perception differences.

Table 3. Mean difference among variables.

\begin{tabular}{|c|c|c|c|c|c|c|c|c|c|}
\hline \multicolumn{2}{|c|}{ Nations } & \multicolumn{8}{|c|}{ Mean Difference (D-(D) } \\
\hline (1) & (1) & IND & COL & UA & $\begin{array}{l}\text { Effect on } \\
\text { others (a) }\end{array}$ & $\begin{array}{l}\text { Effect on } \\
\text { self (b) }\end{array}$ & $\begin{array}{c}\text { TPP } \\
\text { (c=a-b) }\end{array}$ & Regulate & Donate \\
\hline \multirow[t]{3}{*}{ US } & $\mathrm{KO}$ & 0.1176 & -0.2385 & $-0.7033^{* *}$ & 0.2184 & $-0.3893^{*}$ & $0.6077^{*}$ & $-0.5450^{* *}$ & -0.1641 \\
\hline & $\mathrm{SP}$ & $0.7124^{* *}$ & $-0.5233^{* *}$ & -0.1165 & 0.3426 & 0.3201 & 0.0226 & -0.0625 & $0.6704^{* *}$ \\
\hline & IN & -0.0481 & $-1.1210^{* *}$ & $-0.3475^{* *}$ & $-0.6332^{* *}$ & $-1.3517^{* *}$ & $0.7185^{*}$ & $-0.7639^{* *}$ & $-0.5250^{* *}$ \\
\hline \multirow[t]{2}{*}{$\mathrm{KO}$} & $\mathrm{SP}$ & $0.5947^{* *}$ & $-0.2848^{*}$ & $0.5868^{* *}$ & 0.1242 & $0.7093^{* *}$ & $-0.5851^{*}$ & $0.4826^{*}$ & $0.8344^{* * *}$ \\
\hline & IN & -0.1658 & $-0.8825^{* *}$ & $0.3558^{* *}$ & $-0.8516^{* *}$ & $-0.9624^{* *}$ & 0.1108 & -0.2189 & -0.3610 \\
\hline ES & IN & $-0.7605^{* *}$ & $-0.5977^{* *}$ & -0.2310 & $-0.9758^{* *}$ & $-1.6717^{* *}$ & $0.6959^{*}$ & $-0.7014^{* *}$ & $-1.1954^{* *}$ \\
\hline \multicolumn{2}{|c|}{$F(3,766)=$} & $22.397^{* *}$ & $41.832^{* *}$ & $20.221^{* *}$ & $19.439^{* *}$ & $40.756^{* *}$ & $12.833^{* *}$ & $9.991^{* *}$ & $20.031^{* *}$ \\
\hline
\end{tabular}

Asian countries did not show much difference in the presumed media effect on self and others. However, people in Western countries differ in their presumed media effect on self and others. Thus, the third person perceptions were more salient in the Western countries than in the Asian countries. Moreover, respondents in Asian countries support regulation for fake news on global warming than those in Western countries did. Comparisons between US citizens and Korean citizens as well as US citizens and Indian citizens show that larger IND contributes to greater third person perceptions. However, more regulations happen in smaller IND societies such as Korea and India. Conversely, more support for regulation and donation occur the larger COL and UA a society has.

\subsection{Relations between Third Person Perception and Cultural Constructs}

Table 4 shows all three cultural constructs (IND, COL, and UA) have positive associations with the presumed media effect and support for censorship as well as intention to donate money. However, no statistically meaningful correlations exist between IND and third person perception. Moreover, the study found negative correlations between COL and third person perception. Support for censorship positively correlates with IND, COL, and UA. However, the study did not find any significant association between the third person perception and the behavioral components. Accordingly, the study does not support hypotheses 3-1 and 3-2.

Table 4. Correlations among variables $(n=770)$.

\begin{tabular}{|c|c|c|c|c|c|c|c|c|c|}
\hline & & (1) & (2) & (3) & (4) & (5) & (6) & (7) & (8) \\
\hline (1) & IND & & & & & & & & \\
\hline (2) & $\mathrm{COL}$ & $0.197^{* *}$ & & & & & & & \\
\hline (3) & UA & $0.161^{* *}$ & $0.307^{* *}$ & & & & & & \\
\hline (4) & Effect on self & $0.078^{*}$ & $0.288^{* *}$ & $0.202^{* *}$ & & & & & \\
\hline (5) & Effect on others & $0.156^{* *}$ & $0.245^{* *}$ & $0.218^{* *}$ & $0.512^{* *}$ & & & & \\
\hline (6) & $\mathrm{TPP}^{1}$ & 0.058 & $-0.089^{*}$ & -0.020 & $-0.619^{* *}$ & $0.358^{* *}$ & & & \\
\hline (7) & Regulation & 0.056 & $0.206^{* *}$ & $0.268^{* *}$ & $0.200^{* *}$ & $0.167^{* *}$ & -0.064 & & \\
\hline & Donation & $0.171^{* *}$ & $0.250^{* *}$ & $0.187^{* *}$ & $0.267^{* *}$ & $0.319^{* *}$ & 0.002 & $0.306^{* *}$ & \\
\hline
\end{tabular}

\subsection{Path Analysis of Cultural Constructs toward the Third Person Perception and its Corrective Actions}

Using Amos, the study conducted a path analysis with maximum likelihood estimation (See Figure 1). The ration of the $\chi^{2}$ to the degree of freedom $\left(\chi^{2} / \mathrm{df}\right)$ was 2.311 . Overall model fits the data well, (standard root mean square residual $[\mathrm{RMSEA}]=0.04$, confidence interval $[\mathrm{CI}]$ for RMSEA $=0.04$, $\mathrm{CFI}=0.96$, TLI.94), based on the cutoff criteria recommended by Hu and Bentler [57]. 


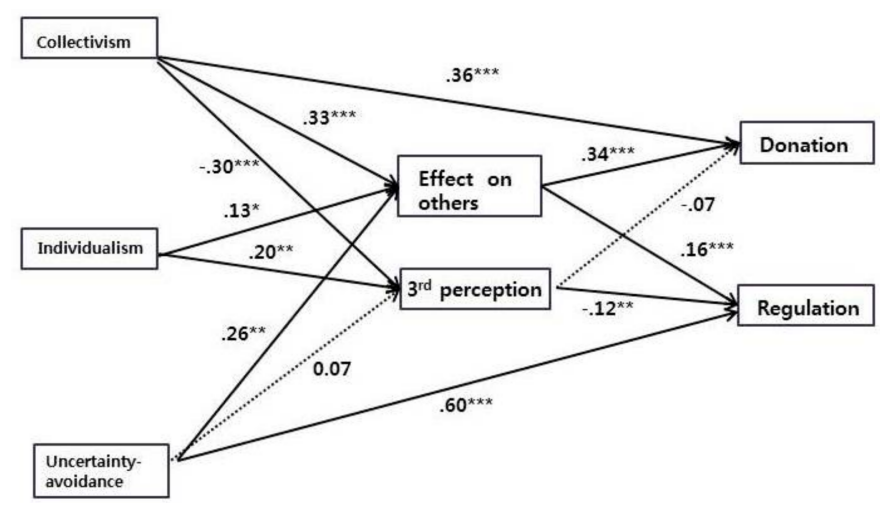

Figure 1. The result of path analysis; ${ }^{*} p<0.05,{ }^{* *} p<0.01,{ }^{* * *} p<0.001$.

The proposed path model hypothesized that COL and IND predict the third person perception. Consistent with the prediction, as IND increases, the third person perception increases (supporting H2-1). However, when COL scores increase, then the third person perceptions decrease (supporting $\mathrm{H} 2-2)$. The study hypothesized that the presumed media effect on others predicted both intentions to donate and to support for regulation of fake news. As illustrated in the Figure 1, the presumed media effect was a good predictor of related behaviors (supporting H3-2). But the third person perception negatively influenced the regulation, but not donation (partially supporting H3-1). This study also examined the link between cultural constructs and the behavioral component. COL positively associated with the corrective action of donation (supporting H4-1), while UA turned out a positive predictor of support for regulation as a preventive effect (supporting H4-2).

\section{Discussions and Conclusions}

Fake news is "a buzzword of our time" because it threatens the principles of democracy, belief in governance, and trust in journalism [56]. Moreover, it directly influences the way people think about the issue and especially distorts children's view of the world. Even though the audience of fake news is small compared to the real news audience [57], fake news spreads faster and brings more emotional reactions of recipients than real news [58].

Indeed, climate change is one of the few scientific theories that make us examine the whole basis of modern society. Unlike other issues, the issues about climate change raise fundamental questions over humanity's relationship with the rest of the Earth [59]. The dissemination of fake news on global warming may make people perplexed because of rare opportunity to witness the phenomenon directly, except some anecdotes. Therefore, over-estimation of fake news' effect on others as well as under-estimation of those on self tends to occur.

The current study found that the third person perception of fake news on global warming occurred. The gaps between the presumed media effect on self and others were more salient in samples of the United States and Spain than these of India and Korea. This finding coincided with the previous cross-cultural comparisons $[15,40]$. Path analysis showed that self-other disparity in the presumed media effect was related to cultural constructs such as IDN and COL. However, it should be noted that IND contributes to enlargement the gaps between the presumed media effect on self and others but COL devoted to decreasing the gaps.

As Inglehart and Oysterman [60] observe, "High levels of Individualism go with high levels of Autonomy and high levels of Self-expression values ... Societies that rank high on self-expression tend to emphasize individual autonomy and the quality of life, rather than economic and physical security" (p. 137). However, we do not have insufficient evidences to account for the behavioral component of the effect. Thus, the present study uses a new approach with uncertainty, expected to explain why and how the third person perception occurs with both perceptual and behavioral components.

To dates, there are explanations why the third person perception occurs with diverse perspectives: a self-enhancement explanation [8,29] attribution theory [7,61]; and the self-categorization theory [62]. 
Nonetheless, there is not enough evidence to connect the third person perception and the presumed media effect with related behaviors. Thus, this study pursues another explanation with cultural constructs (IND, COL, and UA). The findings of the path analysis with AMOS suggest that IND positively results in the third person perception, while COL and UA lead the regulatory behaviors. However, IND by itself may not always be associated with the third person perception. India had the highest IND score but the smallest third person perception in this study. The reason the smallest third person perception was found in India is because respondents in India had much more over-estimation of in the presumed media effect both on self and others than those in other countries.

Specifically, the study investigated the predictors of corrective actions. The current study also found that the third person perception did not automatically contribute to the corrective behaviors. Instead, the presumed media effect on others turned out a more robust predictor of regulatory behaviors. Moreover, cultural constructs such as COL and UA contributed the magnitudes of effect to the corrective actions. The presumed media effect on others may start with uncertainty because people do not exactly know how the media affects the behavior of others. The higher scores of UA contribute to the increase of the presumed media effect and to more possibility of regulation. Similarly, those who have a strong bond with others may have more worries over the presumed media effect on others and tend to practice corrective actions such as donations.

There are limitations to the current study. First, this study did not use a dichotomy of IND-COL as a bi-polar concept. Instead, the study measured the two constructs separately. Thus, it may be different approach with previous third person effect test in cross-cultural backgrounds. Furthermore, surveys conducted in four countries varied in IND, COL, and UA levels. However, the scores from the four countries were not parallel with those of Hofstede [35] who tested cultural values with employees in working places. The difference may result from the online sampling and general populace in the study.

As Sun et al [27] suggests, the third person perception is not a good predictor of people's preventive behaviors such as support for regulation. The absolute values of self-other disparity were suggested to predict the regulation or donation. Future studies must explore how the presumed media effect, third person perception, and the absolute vales of self-other disparity differently work for the preventive and corrective actions. Future studies must also consider other cultural constructs such as high context versus low context [63] and analytic versus holistic view [64,65] when exploring the relationship between the presumed media effect and its subsequent behaviors.

Funding: This work was supported by the Ministry of Education of the Republic of Korea and the National Research Foundation of Korea (NRF-2016S1A5A8019125).

Conflicts of Interest: The authors declare no conflict of interest.

\section{References}

1. Cook, J.; Ellerton, P.; Kinkead, D. Deconstructing climate misinformation to identify reasoning errors. Environ. Res. Lett. 2018, 13, 024018. [CrossRef]

2. Matthews, D. Donald Trump Has Tweeted Climate Change Skepticism 115 Times. Here's All of it. Vox. 1 July 2019. Available online: https://www.vox.com/policy-and-politics/2017/6/1/15726472/trump-tweetsglobal-warming-paris-climate-agreement (accessed on 29 July 2019).

3. Pierre-Louis, K. It's Cold Outside. Cue the Trump Global Warming Tweet. The New York Times. 28 December 2017. Available online: https://www.nytimes.com/2017/12/28/climate/trump-tweet-global-warming.html (accessed on 28 June 2019).

4. Fake News Threatens a Climate Literate World. Available online: https://www.nature.com/articles/ ncomms15460 (accessed on 17 September 2019).

5. Potter, W.J. Media Effects; SAGE Publications: Thousand Oaks, CA, USA, 2012.

6. Ding, D.; Maibach, E.W.; Zhao, X.; Roser-Renouf, C.; Leiserowitz, A. Support for climate policy and societal action are linked to perceptions about scientific agreement. Nat. Clim. Chang. 2011, 1, 462-466. [CrossRef]

7. Gunther, A. What we think others think: Cause and consequence in the third-person effect. Commun. Res. 1991, 18, 355-372. [CrossRef] 
8. Perloff, R.M. The third-prson effect. In Media Effect: Advances in Theory and Research; Bryant, J., Zillmann, D., Eds.; LEA: Mahwah, NJ, USA, 1989; pp. 489-506.

9. Weiner, B. An attributional theory of achievement motivation and emotion. Psychol. Rev. 1985, 92, 548-573. [CrossRef]

10. Davison, W.P. The third-person effect in communication. Public Opin. Q. 1983, 47, 1-15. [CrossRef]

11. Andsager, J.L.; White, H.A. Self Versus Others: Media, Messages, and the Third-Person Effect; LEM: Mahwah, NJ, USA, 2007.

12. Conners, J.L. Understanding the third-person effect. Commun. Res. Trends 2005, 24, 1-22.

13. Perloff, R.M. The third-person effect: A critical review and synthesis. Media Psychol. 1999, 1, 353-378. [CrossRef]

14. Tewksbury, D.; Moy, P.; Weis, D. Preparations for Y2K: Revising the behavioral component of the third-person effect. J. Commun. 2004, 54, 138-157. [CrossRef]

15. Cho, H.; Han, M. Perceived Effect of the Mass Media on Self vs. Other. J. Asian Pac. Commun. 2004, 14, 299-318. [CrossRef]

16. Detenber, B.H.; Rosenthal, S. Public support for censorship in a highly regulated media environment: The influence of self-construal and TPP over time. Int. J. Public Opin. Res. 2018, 30, 1-23.

17. Hong, S.C. Do cultural values matter? A cross-cultural study of the third-person effect and support for the regulation of violent video games. J. Cross Cult. Psychol. 2015, 46, 964-976. [CrossRef]

18. Inter-Governmental Panel on Climate Change. Climate Change 2013: The Physical Science Basis; IPCC: Geneva, Switzerland, 2013; Available online: https://www.ipcc.ch/pdf/assessmentreport/ar5/wg1/WGIAR5_SPM_ brochure_en.pdf (accessed on 20 June 2019).

19. Mooney, C. What Position Does the Trump Administration Take on Climate Change? All of them. The Washington Post. Available online: https://www.washingtonpost.com/news/energyenvironment/wp/2017/ 12/29/the-trump-administrations-position-on-climate-change-is-all-over-the-place/?noredirect=on\&utm_ term=.c9fd84e6072d (accessed on 29 June 2019).

20. Nuccitelli, D. Fake News Tries to Blame Human-Caused Global Warming on El Niño. The Guardian. Available online: https://www.theguardian.com/environment/climate-consensus-97-per-cent/2016/dec/05/fake-newstries-to-blame-human-caused-global-warming-on-el-nino (accessed on 25 June 2019).

21. Leiserowitz, A.; Maibach, E.; Roser-Renouf, C.; Rosenthal, S.; Cutler, M.; Kotcher, J. Climate Change in the American Mind: March; Yale Program on Climate Change Communication: New Haven, CT, USA, 2018.

22. Quinn, A. Fake news, false beliefs, and the need for truth in journalism. Int. J. Appl. Philos. 2017, 31, 21-29. [CrossRef]

23. Feldman, L.; Myers, T.; Hmielowski, J.; Leiserowitz, A. The mutual reinforcement of media selectivity and effect: Testing the reinforcing spirals framework in the context of global warming. J. Commun. 2014, 64, 590-611. [CrossRef]

24. Levendusky, M.S. Why do partisan media polarize viewers. Am. J. Political Sci. 2013, 57, 611-623. [CrossRef]

25. Nightingale, S.J.; Wade, K.A.; Watson, D.G. Can people identify original and manipulated photos of real-world scenes? Cogn. Res. Princ. Implic. 2017, 2017, 1-21. [CrossRef]

26. Barthel, M.; Mitchell, A.; Holcomb, J. Many Americans believe fake news is sowing confusion. The Pew Research Center. Available online: http://www.journalism.org/2016/12/15/many-americans-believe-fake-newsis-sowing-confusion/ (accessed on 28 May 2019).

27. Paul, B.; Salwen, M.B.; Dupagne, M. The third-person effect: A meta-analysis of the perceptual hypothesis. Mass Commun. Soc. 2000, 3, 57-85. [CrossRef]

28. Sun, Y.; Shen, L.; Pan, Z. On the behavioral component of the third-person effect. Commun. Res. 2008, 35, 257-278. [CrossRef]

29. Gunther, A.C.; Mundy, P. Biased optimism and the third-person effect. Journal. Q. 1993, 70, 58-67. [CrossRef]

30. Heine, S.J.; Lehman, D.R. Cultural variation in unrealistic optimism: Does the West feel more vulnerable than the East. J. Personal. Soc. Psychol. 1995, 68, 595-607. [CrossRef]

31. Kobayashi, C.; Brown, J.D. Self-esteem and self-enhancement in Japan and America. J. Cross Cult. Psychol. 2003, 34, 567-580. [CrossRef]

32. Kurman, J. Why is self-enhancement low in certain collectivist cultures? An investigation of two competing explanations. J. Cross Cult. Psychol. 2003, 34, 496-510. [CrossRef] 
33. Park, H.S.; Lee, H.E.; Choi, H.J.; Lee, D.W.; Ahn, J.; Park, H. Perceived similarity and third-person effect: Media coverage of the shooting incident at Virginia Polytechnic Institute and State University. Soc. Behav. Personal. Int. J. 2014, 42, 539-550. [CrossRef]

34. Wei, R.; Lo, V.H.; Lu, H.Y. The third-person effect of tainted food product recall news: Examining the role of credibility, attention, and elaboration for college students in Taiwan. Journal. Mass Commun. Q. 2010, 87, 598-614. [CrossRef]

35. Hofstede, G.H. Culture's Consequences: Comparing Values, Behaviors, Institutions, and Organizations across Nations; Sage Publications: Thousand Oaks, CA, USA, 2001.

36. Cousins, S.D. Culture and self-perception in Japan and the United States. J. Personal. Soc. Psychol. 1989, 56, 124-131. [CrossRef]

37. Waterman, A.S. Identity formation: Discovery or creation? J. Early Adolesc. 1984, 4, 329-341. [CrossRef]

38. Hui, C.H.; Triandis, H.C. Individualism-collectivism: A study of cross-cultural researchers. J. Cross Cult. Psychol. 1986, 17, 225-248. [CrossRef]

39. Markus, H.R.; Kitayama, S. Culture and the self: Implications for cognition, emotion, and motivation. Psychol. Rev. 1991, 98, 98-253. [CrossRef]

40. Lee, B.; Tamborini, R. Third-Person Effect and Internet Pornography: The Influence of Collectivism and Internet Self-Efficacy. J. Commun. 2005, 55, 292-310. [CrossRef]

41. Jang, S.M.; Kim, J. Third person effects of fake news: Fake news regulation and media literacy interventions. Comput. Hum. Behav. 2018, 80, 295-302. [CrossRef]

42. Lim, J.S. The third-person effect of online advertising of cosmetic surgery: A path model for predicting restrictive versus corrective actions. Journal. Mass Commun. Q. 2017, 94. [CrossRef]

43. Barnidge, M.; Rojas, H. Hostile media perceptions, presumed media influence, and political talk: Expanding he corrective action hypothesis. Int. J. Public Opin. Res. 2014, 26, 135-156. [CrossRef]

44. Gunther, A.C.; Storey, J.D. The Influence of Presumed Influence. J. Commun. 2003, 53, 199-215. [CrossRef]

45. Tsfati, Y.; Cohen, J.; Gunther, A.C. The influence of presumed media influences on news about science and scientists. Sci. Commun. 2011, 33, 143-166. [CrossRef]

46. Aycan, Z. Paternalism: Towards conceptual refinement and operationalization. In Indigenous and Cultural Psychology: Understanding People in Context; Kim, U., Yang, K.-S., Wang, K., Eds.; Springer Science + Business Media: Berlin, Germany, 2006; pp. 445-466. [CrossRef]

47. Golan, G.; Banning, S. Exploring a link between the third-person effect and the theory of reasoned action beneficial ads and social expectations. Am. Behav. Sci. 2008, 52, 208-224. [CrossRef]

48. McLeod, D.M.; Detenber, B.H.; Eveland, W.P. Behind the third-person effect: Differentiating perceptual processes for self and other. J. Commun. 2001, 51, 678-695. [CrossRef]

49. Reid, S.A.; Hogg, M.A. Uncertainty Reduction, Self-Enhancement, and Ingroup Identifiaction. Personal. Soc. Psychol. Bull. 2005, 31, 804-817. [CrossRef]

50. Gahagan, J. Social Interaction and its Management; Routledge: New York, NY, USA, 1984.

51. Shuper, P.A.; Sorrentino, R.M.; Otsubo, Y.; Hodson, G.; Walker, A.M. A theory of uncertainty orientation: Implications for the study of individual differences within and across cultures. J. Cross Cult. Psychol. 2004, 35, 460-480. [CrossRef]

52. Hui, C.H. Measurement of individualism-collectivism. J. Res. Personal. 1988, 22, 17-36. [CrossRef]

53. Gelfand, M.J.; Triandis, H.C.; Chan, D. Individualism versus collectivism or versus authoritarianism? Eur. J. Soc. Psychol. 1996, 26, 397-410. [CrossRef]

54. Oyserman, D.; Coon, H.M.; Kemmelmeier, M. Rethinking individualism and collectivism: Evaluation of theoretical assumptions and meta-analyses. Psychol. Bull. 2002, 128, 3-72. [CrossRef]

55. Jung, J.M.; Kellaris, J.J. Cross-national differences in proneness to scarcity effect: The moderating roles of familiarity, uncertainty avoidance, and need for cognitive closure. Psychol. Mark. 2004, 21, 739-753. [CrossRef]

56. Douglas, J. Fake news: Improved Critical Literacy Skills Are Key to Telling Fact from Fiction. The Guardian. Available online: https://www.theguardian.com/teacher-network/2017/oct/17/fake-news-improved-criticalliteracy-skills-teaching-young-people (accessed on 20 June 2019).

57. Nielson, J.L. Is 'Fake News' a Fake Problem? The Columbia Journalism Review 2017. Available online: https://www.cjr.org/analysis/fake-news-facebook-audience-drudge-breitbart-study.php (accessed on 24 June 2019). 
58. Vosoughi, S.; Roy, D.; Aral, S. The spread of true and false news online. Science 2018, 359, $1146-1151$. [CrossRef] [PubMed]

59. Maslin, M. Climate Change: A Very Short Introduction, 3rd ed.; Oxford University Press: Oxford, UK, 2014.

60. Inglehart, R.; Welzel, C. Modernization, Cultural Change, and Democracy: The Human Development Sequence; Cambridge University Press: Cambridge, UK, 2005.

61. Rucinski, D.; Salmon, C.T. The 'other' as the vulnerable voter: A study of the third-person effect in the 1988 U.S. presidential campaign. Int. J. Public Opin. Res. 1990, 2, 345-367. [CrossRef]

62. Reid, S.A.; Hogg, M.A. A self-categorization explanation for the third-person effect. Hum. Commun. Res. 2005, 31, 129-161. [CrossRef]

63. Hall, S. Beyond Cultures; Doubleday: New York, NY, USA, 1976.

64. Nisbett, R.E. The Geography of Thought: How Asians and Westerners Think Differently, and Why; Free Press: New York, NY, USA, 2003.

65. Nisbett, R.E.; Peng, K.; Choi, I.; Norenzayan, A. Culture and systems of thought: Holistic versus analytic cognition. Psychol. Rev. 2001, 108, 291-310. [CrossRef]

(C) 2020 by the author. Licensee MDPI, Basel, Switzerland. This article is an open access article distributed under the terms and conditions of the Creative Commons Attribution (CC BY) license (http://creativecommons.org/licenses/by/4.0/). 